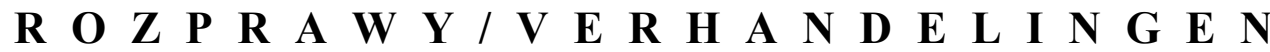

\author{
ROCZNIKI HUMANISTYCZNE \\ Tom LXVIII, zeszyt 5 - 2020 \\ ZESZYT SPECJALNY / SPECIALE UITGAVE \\ DOI: http://dx.doi.org/10.18290/rh20685sp-1
}

REKA BOZZAY

\section{GELOOFSVRIJHEID IN ZEVENBURGEN IN DE VROEGMODERNE TIJD}

\begin{abstract}
A b s t r a ct. Na de overwinning van de Ottomanen in Mohács begon een langdurige strijd om de Hongaarse troon die tot de verdeling van Hongarije in drie delen leidde. János Zsigmond, de zoon van de koning van Hongarije en Isabella Jagiello, werd de vorst van het vorstendom Transsylvanië, maar hij bleef tegelijkertijd vazal van sultan Süleyman II. Er waren drie naties in het vorstendom (Hongaren, Szeklers, Saksen). Ze vormden etnische groepen en hadden hun eigen standen. In de $16^{\mathrm{e}}$ eeuw bekeerden sommigen van hen zich tot protestantse denominaties, anderen van hen bleven katholiek. Religieuze vragen werden besproken op de landdag onder leiding van de humanistische prins János Zsigmond. In dit artikel geef ik een overzicht van de verschillende wetsvoorstellen die de status-quo hebben gewaarborgd tussen de verschillende protestantse kerken en de katholieken.
\end{abstract}

Trefwoorden: vorstendom Transsylvanë; geloofsvrijheid; lutheranisme; calvinisme; unitarisme; catholicisme.

\section{HISTORISCHE ACHTERGROND}

Europa maakte in het begin van de moderne tijd een territoriale en religieuze versnippering mee. De opmars van de Turken splitste Europa in twee: een christelijk en een islamitisch deel, en de reformatie versnipperde de christelijke wereld (de voormalige Universalis Christiana) verder en dat leidde tot religieuze oorlogen (Várkonyi 103).

Het bestaan van het Koninkrijk Hongarije werd door deze Europese crisis ondermijnd. Aan het begin van de zestiende eeuw nam het Turkse gevaar in

Dr. Reka Bozzay is Universitair Hoofdassistent bij de Vakgroep Nederlands van de Universiteit van Debrecen. Zij is gespecialiseerd in interculturele contacten tussen Hongarije en de Lage Landen; Correspondentieadres: Néderlandisztika Tanszék, Debreceni Egyetem, Egyetem tér 1, H-4032 Debrecen; e-mail: rekabozzay@gmail.com. ORCID: https://orcid.org/0000-0002-3057-000X. 
Centraal-Europa toe. De in Hongarije (en in Bohemen) regerende Jagiellodynastie wilde snel een alliantie sluiten met de machtigste heersers van het toenmalige Europa, de Habsburgers. De Hongaarse troonopvolger Lajos (Lodewijk) trouwde met Maria van Habsburg (die later onder de naam Maria van Hongarije als landvoogdes van de Nederlanden bekend werd). Anna, de zus van Lajos, werd aan de broer van de latere keizer Karel V, Ferdinand van Oostenrijk, uitgehuwelijkt (Ronin 92).

Het Turkse gevaar werd in de jaren '20 van de zestiende eeuw steeds ernstiger. Qua omvang en de uitrusting kon het leger van de HongaarsBoheemse koning Lajos niet vergeleken worden met dat van sultan Süleyman II. Het leger van de Ottomanen was een goed opgeleid, staand huurleger, dat in tegenstelling tot de Europese legers nieuwe krachten had, die snel gemobiliseerd konden worden. De Ottomanen wilden niet de Hongaarse troon, maar het gebied van Hongarije veroveren. Volgens Géza Pálffy (41) wilde Süleyman Hongarije tot een Turkse vazalstaat maken. De Hongaren hoopten nog op internationale hulp tegen de vijanden van het christendom. Maar ondanks de financiële steun die de staat uit buitenlandse (onder andere ook Engelse en Portugese) bronnen werd beloofd (Barányi 39) en een internationaal leger grotendeels bestaand uit Midden-Europese soldaten dat naar het zuiden van Hongarije trok, werd het leger van de Hongaarse koning eind augustus 1526 in de slag bij Mohács vernietigd. De aartsbisschoppen van Esztergom en Kalocsa, vijf bisschoppen (de meerderheid van de leiding van de katholieke kerk in Hongarije), honderden edelen en duizenden gewone krijgers sneuvelden op het slagveld. De koning probeerde op zijn paard voor de Turken te vluchten, maar hij viel van zijn zadel en verdronk in een klein riviertje. Na de slag bij Mohács plunderden de Turken Boeda, maar vanwege de herfst trokken ze terug. De weduwe van de koning vluchtte naar Pozsony (Bratislava) en later naar Wenen. Het koninkrijk begon uit elkaar te vallen (Ronin 93).

Kort na het vertrek van de Turken koos een deel van de Hongaarse adel een "nationale" vorst, János Szapolyai, de woiwode van Zevenburgen, het andere deel Ferdinand van Oostenrijk, de zwager van Lajos II, tot koning. Het land had dus twee koningen. Dit leidde tot een lange oorlog tussen beiden. In 1538 sloten zij een vredesverdrag en besloten dat ieder van hen over het door hem bezette gebied zou regeren, en na de dood van János zou Ferdinand het oostelijke deel van Hongarije (Zevenburgen inbegrepen) overnemen. In 1540 overleed János, maar twee weken voor zijn dood kreeg hij een zoon, János Zsigmond. De landdag van Zevenburgen wilde deze als koning 
erkennen en vroeg de sultan om hulp tegen Ferdinand. Boeda werd door Ferdinand belegerd, maar de sultan erkende János Zsigmond als koning van Hongarije en nam Boeda 15 jaar na zijn overwinning bij Mohács in. Hongarije viel daardoor in drie delen uiteen. Het noord-noordwestelijke deel van het land en een klein deel van Kroatië bleven bij de Habsburgers, de sultan kreeg het centrale deel tussen de Donau en de Tisza, een klein deel ten westen van de Donau en een groot deel van Kroatië. Zevenburgen en het oostelijke deel van het land gaf Süleyman aan zijn vazal János Zsigmond, die jaarlijks 10.000 gouden muntstukken als tribuut naar Istanbul moest sturen (Ronin 95-98).

\section{VORSTENDOM ZEVENBURGEN}

Het vorstendom Zevenburgen had al onder de Hongaarse koningen een opmerkelijk eigen leven geleid. Enerzijds speelde hier de ligging van het landsdeel (heuvel- en bergachtig) een rol, anderzijds had dit gedeelte van het land ook een neiging tot individualisme. Deze speciale ontwikkeling werd ook door de herkomst en maatschappelijke status van de inwoners bepaald (Völkl 46-47). Hoewel de vorst nu het gezag van de sultan moest erkennen, beschouwden de inwoners van het vorstendom zich als onderdanen van de Heilige Kroon van Hongarije. Het westelijke deel van Hongarije viel toe aan de Habsburgers en werd dus door een buitenlandse, Duitssprekende dynastie geregeerd, maar in Zevenburgen kwamen alle vorsten uit Hongaarse adellijke geslachten. De standen van Zevenburgen werden door de vorst bijeengeroepen, beschouwden hun vorstendom als een deel van het koninkrijk Hongarije en de Habsburgse koningen als legitieme koningen, maar tegelijkertijd waren de standen gehecht aan de politieke zelfstandigheid van Zevenburgen (Ronin 104). De standen bestonden uit drie naties (tres nationes): de Hongaarse adel, de autonome Szeklers van Hongaarse komaf met hun edelen aan het hoofd, en de autonome burgers van de "Saksische" steden, die niet door hun aantal maar door hun economische macht van bijzonder belang waren. Deze naties vormden niet alleen etnische groepen, maar ook eigen standen (Völkl 47). Deze geprivilegieerde groepen sloten al in 1437 een politieke alliantie, de zgn. unie van de drie naties (unio trium nationum), en beschermden hun voorrechten tegen het gewone volk. De orthodox-christelijke Roemenen bleven volledig buiten het standensysteem, geen enkele sociale groep van hen werd als natie erkend en ze werden evenmin op de landdagen uitgenodigd (Ronin 104). 


\section{GELOOFSVRAGEN IN ZEVENBURGEN}

Hoewel het Vorstendom Zevenburgen een vazalstaat van de Ottomanen werd, werden het land en de bewoners er niet toe gedwongen zich tot de islam te bekeren. De Ottomanen bekeken de religieuze twisten van de veroverde christelijke staten heel pragmatisch. Ze probeerden zich bij geloofskwesties afzijdig te houden, en als dat niet kon, gaven ze die partij gelijk, wier overwinning voor hen gunstiger was. Onder hun regering kon zich dus ook het protestantisme verspreiden, en dankzij hun bijzondere religieuze tolerantie ook de radicaalste vormen ervan (Ács 21).

De reformatie betekende in Zevenburgen een nog sterkere omwenteling van het geestelijke en politieke leven dan in andere delen van Hongarije. De reformatie vond snel veel volgelingen en de ontwikkeling ervan leidde niet tot het monopolie van één religie, omdat verschillende takken van de reformatie aanhangers onder de Zevenburgse bevolking vonden (Várkonyi 105). De verschillende reformatorische bewegingen bereikten Zevenburgen in golven. In 1526 werd het door Saksen bewoonde Szeben (Sibiu/Hermannstadt/Cibinium) al luthers (Várkonyi 106). Na 1541, in het jaar toen Boeda door de Turken werd ingenomen, bekeerde het overgrote deel van de bevolking van Zevenburgen zich tot het lutheranisme, zodat de oude kerk op een gegeven moment leek te verdwijnen. Sinds 1542 was er geen katholieke bisschop meer (behalve in de korte periode tussen 1551 en 1556 toen Zevenburgen tot Oostenrijk behoorde), hoewel de zetel van de bisschop om juridische redenen nog tot 1556 verder bestond. In 1556 begon ook de secularisering van de katholieke goederen. Toch beleden de heersers János Szapolyai en zijn zoon János Zsigmond nog het katholieke geloof. Alleen bij de Szeklers vond het katholicisme nog aanhang. De natie van de Saksen (Universitas Saxonum) nam in haar geheel in 1544 het lutheranisme aan. Johannes Honter, de stadsdominee van Brassó (Braşov/Kronstadt/Corona), stelde een geloofsbelijdenis (Reformatio Ecclesiae Coronensis ac totius Barcensis provinciae, 1545) gebaseerd op Luthers leer op. Onder de Hongaren traden Ferenc Dávid (Hertel) en Gáspár Heltai (Helth), beide Zevenburgse Saksen, met reformatorische ideeën naar voren. De Zevenburgse Saksen namen de Confessio Augustana in 1572 uiteindelijk stapsgewijs aan (Völkl 47).

De Zwitserse (calvinistische) richting kreeg zijn eerste aanhangers in Kolozsvár (Cluj/Klausenburg/ Claudiopolis). De eerdergenoemde Saksische dominee Ferenc Dávid stond aan het hoofd van deze nieuwe beweging. De stad Kolozsvár ging in 1559 van het lutheranisme naar het calvinisme over. 
Als gevolg van de dogmatische twisten maakten de Saksen zich organisatorisch los van de grotendeels calvinistisch geworden Hongaarse gemeente en stichtten hun eigen nationale Saksische kerk in 1564. De Saksen bleven luthers, de Hongaren gingen in grote meerderheid over tot het calvinisme.

Op kosten van het calvinisme nam het aantal unitariërs toe. De Piëmontese arts, Georg Biandrata, die via Polen naar Zevenburgen was gevlucht en bij het vorstelijke hof werkzaam was, zette met andere mannen samen vaart achter deze religie. De reeds genoemde Ferenc Dávid werd de centrale figuur van deze nieuwe religie. Hij was oorspronkelijk luthers, later calvinistisch, een onrustige geest, die zichzelf en ook anderen snel enthousiast kon maken. Wij moeten hier nog de sekte van de sabbatariërs noemen, een radicale aftakking van de unitariërs, die onder de Hongaarse Szeklers veel aanhangers had. Naast de rooms-katholieken was er nog één niet-protestantse religieuze groep in Zevenburgen aanwezig, die van de orthodox-christenen, die een aanzienlijk deel van de Zevenburgse bevolking vormden en van Roemeense herkomst waren (Völkl 48).

In de loop van de zestiende eeuw werd het overgrote deel van de Zevenburgse bevolking protestants, maar geen enkele confessie kon een overheersende positie bereiken. De religieuze verdeling kwam evenmin per se overeen met de sociale en maatschappelijke verhoudingen. Ook in Zevenburgen moest dus een oplossing gevonden worden voor de religieuze verdeeldheid. In Europa waren er principieel twee praktijken gangbaar: het creëren van een religieus uniforme staat, wat uiteindelijke tot geestelijke terreur en langdurige crises leidde, of wat in het principe van de Godsdienstvrede van Augsburg (cuius regio, eius religio) werd beschreven: het in de handen van de macht leggen van het geweten van de onderdanen (Várkonyi 106).

Hoe werd de religieuze kwestie in Zevenburgen geregeld? In de Hongaarse geschiedschrijving gold het Edict van Torda (Turda/Thorenburg) van 1568 als een derde weg voor de oplossing van de religieuze twisten. Zoals al eerder werd vermeld, werd Zevenburgen in de zestiende eeuw een multiconfessioneel land. Vorst János Zsigmond werd door zijn Pools-Italiaanse moeder Isabella in Zevenburgen en later aan het hof van zijn oom Sigismund II August van Polen katholiek opgevoed. De humanistisch opgevoede Isabella gebruikte bij de opvoeding van haar eigen zoon het boek Institutio Principis Christiani van Erasmus. De daar beschreven principes kwamen de jonge vorst later van pas, hij moest namelijk een nieuwe staat opbouwen. Tussen 1541 en 1570 werden de grondstenen van deze nieuwe staat gelegd: er werden nieuwe staatsinstellingen gesticht en een grondwet ingevoerd. De 
wetten zorgden voor de onaantastbaarheid van het privébezit en de bestrijding van criminaliteit. Maar de wetten vergaven de criminelen met goed gedrag, armen en zwakken werden geholpen en de straffen van criminelen werden niet door de nakomelingen niet "geërfd" (Várkonyi 104). De jonge prins stond open voor het protestantisme en hij bekeerde zich in de jaren vijftig tot het lutheranisme en later onder invloed van zijn hofpredikant Ferenc Dávid tot het unitarisme (Kálmán 65).

\section{WETTEN VAN DE GELOOFSVRIJHEID}

Essentiële interconfessionele vragen werden in Zevenburgen niet door theologische disputen geregeld, maar met wetten van de landdagen. Deze wetten kunnen in de volgende groepen verdeeld worden:

1. ze accepteren de nieuwe confessies en verzekeren hun werkzaamheden $(1545,1548,1552,1564)$

2. ze probeerden een status quo vast te stellen en verdere vernieuwingen te verhinderen $(1544,1545)$;

3. ze waarderen de eigen persoonlijkheid $(1545,1557)$.

Tussen 1566 en 1571 werden door de landdagen belangrijke vragen met betrekking tot de geloofsvrijheid behandeld. De wet van 1568 werd - ook op Europees niveau - één van de belangrijkste. Deze wet bracht vier vernieuwingen met zich mee (Várkonyi 106-107):

1. de wet liet de dominees toe het evangelie op hun eigen manier uit te leggen;

2. de keuze voor een predikant werd een recht van de gemeente, dus niet de staat of een landsheer, maar de steden, marktplaatsen en dorpen konden in gewetensvragen zelf een beslissing nemen;

3. de wet beschermde de predikanten die het evangelie op hun eigen manier interpreteren en ook de gemeente die voor de bewuste predikant heeft gekozen;

4. de wet declareert het principe van gewetensvrijheid.

In de daaropvolgende jaren werden ook andere wetten aangenomen in verband met de religievrijheid in Zevenburgen. Volgens de meeste Hongaarse en buitenlandse historici waren de tussen 1568 en 1571 uitgevaardigde wetten van bijzonder belang, omdat ze de orde en rust van het land garandeerden, en dit was een belangrijke voorwaarde voor het voortbestaan van de etnisch en confessioneel heterogene staat. In de Hongaarse en buiten- 
landse geschiedschrijving is algemeen aanvaard dat ten laatste in januari 1571 de vier gerecipieerde religies (receptae religiones): katholicisme, lutheranisme, calvinisme en unitarisme, wettelijk werden erkend, en in die periode werden ook de orthodoxe christenen ten minste getolereerd (Balázs 55).

Toch bewijst onderzoek van de laatste decennia dat de erkenning van de katholieken als gelijkwaardige en gerecipieerde religie nog enkele jaren op zich liet wachten. In een wet uit 1566 werd namelijk over 'afgodendienaars' gesproken die moeten worden uitgewezen. Volgens Katalin Péter (45-46) is deze wet een resultaat van de gebeurtenissen van de jaren voor 1566 (confiscatie van katholieke goederen, niet-invulling van de zetel van de bisschop etc.) en hier werd de katholieken ook institutioneel het recht ontnomen hun geloof vrij te beoefenen. Sinds 1566 kwam in de wetteksten de vrije uitleg van het evangelie voor en dit werd tegenover het vereren van afgoden gesteld. We zien dus dat in deze wetteksten alleen de verspreiding van het protestantse geloof werd gesteund (Balázs 62).

De wetten uit de periode 1568 en 1571 die de religievrijheid declareren, vermelden echter niet voor welke religies deze vrijheid gold. Volgens Mihály Balázs is dat een gevolg van het feit dat de confessies in Zevenburgen in deze periode nog geen afgesloten, dogmatisch afgebakende kerkelijke structuren hadden. Dit gold voor de Saksisch-lutherse kerk, en nog meer voor de latere calvinistische en unitarische kerken. Onder de kerkelijke jurisdictie van de Saksisch-lutherse bisschop vielen in die jaren namelijk niet alleen de gemeenten die de Confessio Augustana aanvaardden, dus er was nog geen territoriaal-nationale lutherse kerk ontstaan. De grotendeels door Hongaren bewoonde delen van Zevenburgen vielen onder de jurisdictie van de bisschop van Kolozsvár, en de meerderheid van de gemeenten daar volgde de Helvetische leer van het Heilig Avondmaal. Er was ook een andere bisschop met zetel in Debrecen onder wiens jurisdictie niet alleen de gemeenten van de omliggende gebieden vielen, maar ook die op Turks of Habsburgs gebied. In deze periode was er nog geen unitarische confessie. De eerste discussies, aangespoord door de unitariërs, werden al in 1566 gevoerd, maar de eerste werken die voor een breder publiek werden geschreven, verschenen pas in de tweede helft van 1567, en in januari 1568 waren er nog geen geloofsdiscussies gevoerd die grotere publiciteit hadden gekregen. In het begin van de jaren 1570 was er ook geen calvinistische kerk met eigen organisatie. Er waren alleen gemeenten die de Helvetische leer van het Heilig Avondmaal accepteerden en niet verder wilden gaan naar het unitarisme. Maar ook deze gemeenten stonden onder de jurisdictie van de steeds radi- 
caler denkende bisschop Ferenc Dávid, die de leer van de Heilige Drievuldigheid steeds kritischer bekeek en ook in andere punten steeds meer afweek van de Helvetische reformatoren (Balázs 58-60).

De wetten van 1568 en 1571 regelden de relatie tussen de bisschoppen en de gemeenten en verboden het de bisschoppen om over theologische opvattingen van predikanten die onder hun jurisdictie vielen te oordelen. Volgens de wet van 1571 moesten de bisschoppen niet op de theologische opvattingen, maar op de moraal van de predikanten letten. Men wilde dus vermijden dat theologisch-dogmatische discussies de nieuw ontstane kerken en hun leer vernietigden. Zo probeerde de staat de orde te handhaven. Als gevolg hiervan werden theologische discussies op een lager niveau gevoerd, namelijk op het niveau van de gemeenten (Balázs 61). Volgens de wetten kozen niet de individuen maar gemeenten voor predikanten met verschillende theologische opvattingen, en later sprak de wet evenmin over de relatie tussen de individuele gelovigen en de bisschop. Er stond alleen dat de predikanten van het dogmatische toezicht werden bevrijd. De wet was dus niet hierom modern, omdat hij over de keuze van het individu sprak, maar omdat hij buiten beschouwing liet welke toestemming men nodig had om predikant te worden (Balázs 63).

De wetten behandelden in deze periode ook de 'bijzondere blindheid' van de orthodoxe priesters van de Roemenen. Feitelijk werden ze op dezelfde manier behandeld als de katholieken: ze werden als afgodendienaars beschouwd. Men trachtte ook onder de orthodoxe Roemenen de gedachten van de reformatie te verspreiden met als doel om een uniform-protestantse staat te vormen. Hierbij werd de (ook schriftelijke) Roemeenstalige cultuur gesteund om het nieuwe geloof onder de Roemenen in hun moedertaal te verspreiden, maar tegelijkertijd werd weinig sensibiliteit getoond voor andere componenten van de laatmiddeleeuwse orthodoxe Roemeense cultuur (Balázs 65).

$\mathrm{Na}$ de dood van János Zsigmond (1571) werd de machtigste aristocraat van Zevenburgen, de katholieke István Báthory, tot vorst gekozen. Hij regeerde van 1571 tot 1586 . De standen leken zich dus weinig zorgen te maken dat het protestantisme zou verdwijnen. De katholieke vorst eerbiedigde weliswaar de wetten van het land, maar nam tegelijkertijd stappen om de kerkelijke verhoudingen te veranderen. Hij voerde de censuur in, verbood allerlei verdere kerkelijke vernieuwingen en probeerde de godsdienstbeoefening van de Unitariërs in te perken. Dit leidde ertoe dat rond 1576 de gemeenschappelijke Kerk van de Hongaren werd opgesplitst en een calvinistische en een unitarische kerk zijn ontstaan. Verder probeerde Báthory, en 
later ook zijn oudere broer Kristóf, het katholicisme in Zevenburgen weer in te voeren. De jezuïeten kwamen in 1579 het land binnen en in Kolozsvár werd in 1581 een jezuïetencollege gesticht. In hetzelfde jaar werd een wet aangenomen die het aan de jezuïeten mogelijk maakte om zich in bepaalde gebieden te vestigen, indien na inspectie van een vorstelijke en twee lokale gedelegeerden werd vastgesteld dat in het gebied katholieken in de meerderheid waren. In deze wet van 1581 werd eerst het begrip recepta religio gebruikt. Hiermee werd alleen naar protestantse kerkgenootschappen (luthers, calvinistisch, unitarisch) verwezen en de libertas religionis gold eigenlijk alleen voor de protestantse kerken. De verhouding tussen de protestanten en de jezuïeten bleef gespannen en de orde moest in 1588 Zevenburgen weer verlaten. Toch kon de verandering niet meer gestopt worden. In de wet van de landdag van 1591 werd niet alleen nauwkeurig beschreven welke gebieden de jezuïeten moesten opgeven, maar werden ook bijzondere maatregelen getroffen voor bij naam genoemde katholieke groepen. Deze katholieken behoorden weliswaar nog niet tot de gerecipieerde religieuze groeperingen, maar sinds de overwinning van het protestantisme werden nu voor het eerst de Szeklers van de provincie Csík genoemd, die vasthielden aan hun katholieke geloof. Vier jaar later werden in 1595 op de landdag van Gyulafehérvár (Alba Julia/Weissenburg) ook de katolieken met name bij de gerecipieerde religies genoemd. Hiermee bevestigde de wet een al langer levende traditie schriftelijk en werd de institutionalisering van de vier gerecipieerde religies in Zevenburgen afgesloten (Balázs 65-70). De orthodoxen werden echter ook hierna niet als gerecipieerde religie erkend. Een verklaring hiervoor kan zijn dat de orthodoxe bisschopszetel buiten het land lag, de Roemenen in Zevenburgen zelf geen eigen kerkelijke instellingen tot stand hadden gebracht en de taal van de kerk het Kerkslavisch bleef. Een deel van de Roemenen leefde van transhumance, ${ }^{1}$ daarom wisselden ze elk seizoen hun woonplaats tussen de twee kanten van de Karpaten, tussen het Vorstendom Zevenburgen en de Roemeense vorstendommen van Moldau en Walachije (Várkonyi 107).

\footnotetext{
${ }^{1}$ Transhumance is het regelmatig verplaatsen van vee afhankelijk van de seizoenen (hoger gelegen weiden in de zomer en lager gelegen in de winter). De veehoeders leven vaak in tijdelijke of verplaatsbare woningen, de boeren wel in vaste huizen in de dalen.
} 


\section{VOORTBESTAAN VAN DE RELIGIEUZE TOLERANTIE}

De zestiende-eeuwse wetten van de landdagen zorgden voor rust en orde in het land en verhinderden dat één van de religies voorrang kreeg. Anderzijds conserveerden ze de kerkelijke situatie en boden ze nauwelijks mogelijkheid voor verdere vernieuwingen.

Hoewel andere religies in de daaropvolgende decennia ook niet onder de gerecipieerden werden genoemd, bleef Zevenburgen een land dat veel vluchtelingen opnam. Hier konden de uit Moravië verdreven anabaptisten, de uit Polen verjaagde unitariërs, vluchtelingen uit Hongarije ongeacht hun religie, Armeense, Joodse en Griekse kooplui, leden van de Levantse Compagnie, en orthodoxe Roemenen opgenomen worden. Vorst Gábor Bethlen (1613-1629) liet de Joden ook toe hun religie vrij te beoefenen zolang ze daarmee anderen niet lastigvielen. Verder schreef hij hun in 1623 ook voor om christelijke kleren zonder allerlei tekens te dragen, omdat de discriminatie vernederend zou zijn. In zijn testament schreef hij ook dat het land gevaar kan vermijden als er geen religieuze twisten ontstaan. De gewetensvrijheid en de vrije keuze van religie door horigen en gemeenten werden in 1652 in het wetboek Approbatae Constitutiones van vorst György II Rákóczi (1621-1660) bevestigd. Na de hereniging van Hongarije bij de Vrede van Karlowitz uit 1699 onder het absolutistische Habsburgs bewind wilde Ferenc II Rákóczi binnen het koninkrijk een nieuwe Hongaarse staat stichten (Várkonyi 108). In de landdag van Szécsény in 1705 werd de geloofsvrijheid aangekondigd, de macht van de landheer beperkt en op grond van het aantal gelovigen het kerkgebouw aan de grootste religieuze gemeenschap toegekend. De meerderheid moest echter de religieuze minderheden helpen om een eigen kerk te (laten) bouwen (Rumy 207-209). Na het neerslaan van de Rákóczi-opstand golden echter zowel in Hongarije als in Zevenburgen absolutistische principes. De katholieke religie kreeg van de Habsburgers voorrang en protestanten (alle confessies) moesten in de daaropvolgende eeuwen vechten voor hun voortbestaan. Hiermee eindigde de Zevenburgse tolerantiepraktijk.

\section{BIBLIOGRAFIE}

Ács, Pál. "Bécsi és magyar renegátok mint szultáni tolmácsok: Mahmud és Murád [Weense en Hongaarse renegaten en tolken van de sultan: Mahmoed en Murad]". Tanulmányok Szakály Ferenc emlékére [Studies ter nagedachtenis van Ferenc Szakály], ed. Fodor Pál, Géza Pálffy, István György Tóth, Budapest, MTA TKI Gazdaság- és Társadalomtörténeti Kutatócsoport, 2002, pp. 15-28. 
Balázs, Mihály. “ ‘A hit... vallásból lészön’. Megjegyzések a négy bevett vallás intézményesüléséhez a 16. századi Erdélyben ['Het geloof... ontstaat door religie.' Opmerkingen over de institutionalisering van de vier gerecipieerde religies in de 16de eeuw in Zevenburgen]. Tanulmányok Szakály Ferenc emlékére [Studies ter nagedachtenis van Ferenc Szakály], ed. Fodor Pál, Géza Pálffy, István GyörgyTóth, Budapest, MTA TKI Gazdaság- és Társadalomtörténeti Kutatócsoport, 2002, pp. 51-73.

Barányi, Attila. "Magyarország és a külső segítség 1526-ban [Hongarije en hulp van buitenaf in 1526]”. "Nekünk mégis Mohács kell...”, II. Lajos király rejtélyes halála és különbözö temetései [Maar we willen toch Mohács..." De mysterieuze dood en verschillende begravingen van koning Lajos II], ed. Gábor Farkas, Zsolt Szebelédi, Bernadett Varga, Magyar Tudományos Akadémia Bölcsészettudományi Kutatóközpont Széchényi Könyvtár, 2016, pp. 35-54.

Kálmán, Benda. “Az 1568. évi tordai országgyűlés és az erdélyi vallásszabadság [De landdag van Torda in 1568 en de geloofsvrijheid van Zevenburgen]". Fejedelemasszonyok és vallásszabadság Erdélyben [Vorstinnen en geloofsvrijheid in Zevenburgen], ed. Erzsébet Udvarhelyi, Veszprém, Károly Nagy, 2016, pp. 63-66.

Pálffy, Géza. A Magyar Királyság és a Habsburg Monarchia a 16. században [Het Hongaarse Koninkrijk en de Habsburgse Monarchie in de 16 eeuw]. História Könyvtar, 2010.

Péter, Katalin. "Die Reformation in Ungarn”. Études historiques hongroises 4. European Intellectual Trends and Hungary, ed. Ferenc Glatz, Budapest, MTA Történettudományi Intézet, 1990, pp. 39-52.

Ronin, Vladimir. Geschiedenis van Hongarije: van Árpád tot Árpád Göncz. Antwerpen/Apeldoorn, Garant, 2003.

Rumy, Károly György, editor. Monumenta Hungarica. Az az magyar emlékezetes írások [Gedenkwaardige Hongaarse schriften]. Pest, Trattner, 1816.

Várkonyi, Ágnes R. "Pro quiete regni - Az ország nyugalmáért [Voor de rust van het land]”. Korunk, nr 6, 1993, pp. 103-109.

Völkl, Ekkehard. "Möglichkeiten und Grenzen der konfessionellen Toleranz dargestellt am Beispiel Siebenbürgens im 16. Jahrhundert”. Ungarn-Jahrbuch, vol. 4, 1972, pp. 46-60.

\section{WOLNOŚĆ RELIGII W SIEDMIOGRODZIE WE WCZESNYM OKRESIE CZASÓW NOWOŻYTNYCH}

$$
\text { Streszczenie }
$$

Po zwycięstwie Turków pod Mohaczem rozpoczęła się długa bitwa o tron węgierski, która doprowadziła do podziału Węgier na trzy części. Jan II Zygmunt Zápolya, syn króla Węgier i Izabelli Jagiellonki, został pierwszym księciem Siedmiogrodu, a jednocześnie pozostał wasalem sułtana Sulejmana II. W księstwie znajdowały się wtedy trzy narody (Węgrzy, Seklerzy, Saksowie). Tworzyli oni grupy etniczne i mieli własne ustalone pozycje. W XVI wieku niektórzy $\mathrm{z}$ nich przeszli na wyznania protestanckie, inni pozostali katolikami. Kwestie religijne omawiane były podczas obrad pod przewodnictwem humanisty, księcia Jana II Zygmunta. W niniejszym artykule przedstawiono przegląd różnych wniosków legislacyjnych, które zagwarantowały status quo między różnymi kościołami protestanckimi a katolikami.

\section{Przełożyla Beata Popławska}

Słowa kluczowe: księstwo Transylwanii; wolność wyznania; luteranizm; kalwinizm; unitizm; katolicyzm. 


\section{FREEDOM OF RELIGION IN TRANSYLVANIA \\ IN EARLY MODERN TIMES}

\section{S u m m a r y}

After the victory of the Ottomans in Mohács, a long war started for the Hungarian throne which led to the division of Hungary into three parts. János Zsigmond, the son of the king of Hungary and Isabella of Poland became the prince of the Principality of Transylvania, being also a vassal of Sultan Suleiman II. There were three nations in the Principality (Hungarians, Szeklers, Saxons). They formed ethnic groups and estates. In the $16^{\text {th }}$ century some of them converted to protestant religions, some of them remained catholic. Religious questions were discussed on the Diet ruled by the humanist prince János Zsigmond. In this paper I give an overview of the different bills which ensured the status quo among the different protestant religions and the Catholics.

Key words: Principality Transylvania; freedom of religion; Lutheranism; Calvinism; Unitarism; Catholicism. 